\title{
An Integrated Bearing Parameter Identification Approach Using A Nonlinear Optimisation Scheme
}

\author{
Rajasekhara Reddy Mutra $^{1^{*}}$ and J. Srinivas ${ }^{2}$ \\ ${ }^{1}$ Mechanical Engineering, National Institute of Technology, Rourkela, \\ 769008 Rourkela, Odisha, India \\ ${ }^{2}$ Faculty of Mechanical Engineering, National Institute of Technology, Rourkela, \\ 769008 Rourkela, Odisha, India \\ "Email: rajmech03@gmail.com \\ Phone: +91 661 2462503; Fax: +91661 2462022
}

\begin{abstract}
In system identification process, efficient global optimisation schemes play a vital role. In the present work, an effective optimisation-based identification methodology of bearing stiffness and damping coefficients using the bearing response data is proposed. The flexible rotor is initially analysed by finite element model with nonlinear bearing forces. The dynamic equations of rotor are solved to obtain the bearing responses in frequency domain at different operating speeds. The equivalent speed dependent parameters of stiffness and damping are then obtained by solving an error-based optimal formulation via modified particle-swarm optimisation scheme. The robustness of the approach is tested with added input noise. The approach is illustrated with the simulation results of rotor supported on full floating ring bearings and using an experimental data obtained from a rotor supported on two similar journal bearings. The error in identification is not exceeding five percent. The modified particle swarm optimisation is converging faster, and it is taking less computational time. The results are shown in the forms of graphs and tables.
\end{abstract}

Keywords: Bearing force coefficients; floating ring bearings; frequency response; hydrodynamic forces; nonlinear optimisation.

\section{INTRODUCTION}

Identification of bearing parameters is one of essential problems in rotor dynamics. The working speeds of certain industrial machinery are often very high, and, in such systems, even small vibrations persist for long time which leads to decrease in their life-span severely or even distorts the bearings fully. These high-speed rotors are often supported on various types of bearings and have unbalance and coupling forces leading to complex overall dynamics. The fluid film bearings are widely used in rotors due to their high damping and stiffness capabilities. Commonly linearised spring damper models are used at the bearing nodes for the system response and stability analysis of the rotor bearing system. Nevertheless, these parameters do not remain constant throughout the operating speed range and several approaches were proposed to identify such parameters. Changes in high speed rotor systems supported by nonlinear hydrodynamic forces of floating ring journal bearings were analysed thoroughly in literature [1-4]. Bearing parameters were obtained for plain and aerostatic journal bearings [5, 6]. Both linear and nonlinear bearing stiffness of journal bearing were estimated by perturbation technique using two- 
dimensional Newton-Raphson iteration method on locating the journal equilibrium positions [7].

Methodology for prediction of sixteen dynamic coefficients for journal bearings in a rotor from experimental unbalance responses was presented earlier [8, 9]. Identification procedures of other bearing types are also found in various earlier works. A method with multi-frequency excitation for measurement of equivalent stiffness and damping of active magnetic bearing rotor was presented by Jiang et al. [10]. Based on the unbalance response [11, 12] and frequency characteristics [13], similar kinds of magnetic bearing parameter identification approaches were presented. Likewise for ball bearing systems, the parameters were identified with simulated and experimental data [14]. Likewise, linear and nonlinear bearing coefficients of oil-free bearings like gas-foil [15-19] and gas-film bearings [20, 21] have been also obtained. Response based identification methodologies for tilting pad journal bearings were proposed in literature [22-24]. Existing procedures for identification of bearing parameters were summarised in some review works $[25,26]$.

Hydrodynamic bearing forces are highly nonlinear and parametric in nature. Formulating an equivalent linear model is a highly involved procedure. For hydrodynamic journal bearings, a method of field estimation of parameters of stiffness and damping was illustrated [27] using measured responses at both shaft and housing locations. An experimental approach was proposed by Zhou et al. [28] to predict the parameters of stiffness and damping via the least-square minimisation under different operating conditions. A procedure to predict the rotor dynamic force coefficients of series bearing-supports was explored for impact and unbalance from the field measurements [29]. For estimation of bearing coefficients and unbalance from the measured responses, an optimisation based strategy was proposed by Kim et al. [30]. Kriging surrogate model together with differential evolution optimisation scheme was implemented $[31,32]$ to predict the bearing parameters. A modal parameter genetic time domain identification approach has been proposed [33] to know the characteristics of bearing using a multifrequency signal decomposition technology. Prediction of bearing parameter information chart is therefore very important task and a generalised methodology is therefore necessary to obtain the parameters conveniently.

Although many studies were found in literature, few works have only focused such estimation approach based on correlating the real time data with model-based outputs. In the present work, the speed dependent stiffness and damping parameters of the floating ring bearing system are obtained by minimising the average error in radial amplitudes between the measured and predicted values. Initially the rotor-bearing system is analysed by finite element model with nonlinear bearing forces and the unbalance response at bearing nodes is obtained at different speeds of operation. In the next stage, the rotor responses are generated by idealising the bearings as uncertain spring-damper system, whose parameters are to be correctly predicted. A modified particle swarm optimisation scheme is implemented to minimise the defined radial errors so as to achieve the correct set of stiffness and damping parameters. Robustness of methodology is tested with induction of noise to the measured data. The generalised approach is implemented further for prediction of bearing coefficients of an experimental rotor mounted on hydrodynamic journal bearings.

The paper is explained as follows: section- 2 describes the mathematical modelling of rotor system using finite analysis, the expression of nonlinear bearing forces as well as the dynamic formulation of equivalent lumped parameter model of the rotor-bearing system. Section-3 presents the methodology employed and the proposed optimisation 
scheme in brief. Section- 4 gives the results and discussion of two cases considered in the analysis.

\section{DYNAMIC MODEL OF A ROTOR BEARING SYSTEM}

The dynamic model of the flexible rotor dynamic system is formulated using quasi-finite element analysis with lumped floating ring masses considered at the bearing locations. The rotor is treated as flexible component and disks are treated as rigid. Each individual node has 4 degrees of freedom $(D O F)$ which includes two translations $(v, w)$ and two bending slopes $(\varphi x, \varphi y)$. The kinetic and potential energy expressions of the revolving shaft element can be expressed as below:

$$
\begin{aligned}
& \mathrm{T}_{\mathrm{el}}=\int \frac{1}{2} \rho\left\{\mathrm{A}_{\mathrm{s}}\left(\dot{\mathrm{v}}^{2}+\dot{\mathrm{w}}^{2}\right)+\mathrm{I}_{\mathrm{d}}\left(\dot{\phi}_{\mathrm{x}}^{2}+\dot{\phi}_{\mathrm{y}}^{2}\right)+\mathrm{I}_{\mathrm{p}}\left[\omega^{2}+\omega\left(\dot{\phi}_{\mathrm{x}} \phi_{\mathrm{y}}-\dot{\phi}_{\mathrm{y}} \phi_{\mathrm{x}}\right)\right]\right\} \mathrm{ds} \\
& \mathrm{U}_{\mathrm{el}}=\int \frac{1}{2}\left\{\mathrm{EI}\left(\phi_{\mathrm{x}}^{\prime 2}+\phi_{\mathrm{y}}^{\prime 2}\right)+\mathrm{kGA}\left[\left(\phi_{\mathrm{y}}-\mathrm{v}^{\prime}\right)^{2}\right]\right\} \mathrm{ds}
\end{aligned}
$$

Each disk kinetic energy can be expressed as Eq. (3).

$$
\mathrm{T}_{\mathrm{d}}=\frac{1}{2} \mathrm{~m}_{\mathrm{d}}\left(\dot{\mathrm{v}}^{2}+\dot{\mathrm{w}}^{2}\right)+\frac{1}{2} \mathrm{~J}_{\mathrm{d}}\left(\dot{\phi}_{\mathrm{x}}^{2}+\phi_{\mathrm{y}}^{2}\right)+\frac{1}{2} \mathrm{~J}_{\mathrm{p}}\left[\omega^{2}+\omega\left(\phi_{\mathrm{x}} \phi_{\mathrm{y}}-\phi_{\mathrm{y}} \phi_{\mathrm{x}}\right)\right]
$$

The virtual work done by unbalance forces at the disks can be expressed as Eq. (4).

$$
\delta W=m_{d 1} r_{1} \omega^{2}\left(v_{1} \cos \omega t+w_{1} \sin \omega t\right)+m_{d 2} r_{2} \omega^{2}\left(v_{2} \cos \omega t+w \sin \omega t\right)
$$

Using Hamilton principle,

$\delta \int(\mathrm{T}-\mathrm{V}+\mathrm{W}) \mathrm{dt}=0$

with $\delta$ denote the variational symbol, the motion of equation of the rotor alone is written as:

$\mathrm{Mü}+[\mathrm{C}+\Omega \mathrm{G}] \dot{\mathrm{u}}+\mathrm{Ku}=\mathrm{F}_{\mathrm{un}}+\mathrm{F}_{\mathrm{i}}$

Here, $u$ denote the displacement vector of size $Q \times 1, F_{u n}$ represents both unbalance and gravity force vector at the disks. $F_{i}$ is the inner oil film force. $\boldsymbol{M}, \boldsymbol{C}, \boldsymbol{G}$ and $\boldsymbol{K}$ denote respectively the assembled system mass, system damping, gyroscopic and stiffness matrices of size $Q \times Q$ The motion of equation of ring is expressed with the help of inner and outer oil film forces, feed pressure of lubricant and floating ring dead weight. The final motion of equation for the floating ring is written as:

$\mathrm{M}_{\mathrm{R}} \ddot{\mathrm{u}}_{\mathrm{R}}=\mathrm{F}_{\mathrm{o}}-\mathrm{F}_{\mathrm{i}}$

where $u_{R}$ denote the displacement vector of the floating rings at two bearings with the size $4 \times 1, \mathbf{M}_{\mathbf{R}}=\operatorname{diag}\left(m_{R}, m_{R}, m_{R}, m_{R}\right)$ is the mass matrix of the rings with size of $4 \times 4$. The outer and inner lubricant film forces of floating ring bearing can be expressed as Fo and Fi. The final assembled equation of motion after combining the rotor and bearing system of equations can be written as follows: 
where $\tilde{\mathrm{u}}=\left[\begin{array}{ll}\mathrm{u} & \mathrm{u}_{\mathrm{R}}\end{array}\right]^{\mathrm{T}}$ is displacement vector matrix of size $(\mathrm{Q}+4) \times 1$ and $\tilde{\mathrm{F}}=\left[\begin{array}{ll}\mathrm{F}_{\mathrm{un}}+\mathrm{F}_{\mathrm{i}} \quad \mathrm{F}_{0}-\mathrm{F}_{\mathrm{i}}\end{array}\right]^{\mathrm{T}}=\tilde{\mathrm{F}}_{\mathrm{un}}+\widetilde{\mathrm{F}}_{\mathrm{b}}$ is bearing forces and unbalance resultant force vector of size $(Q+4) \times 1$. while $\widetilde{\mathrm{M}}=\left[\begin{array}{cc}\mathrm{M} & 0 \\ 0 & \mathrm{M}_{\mathrm{R}}\end{array}\right], \widetilde{\mathrm{C}}=\left[\begin{array}{cc}\mathrm{C}+\Omega \mathrm{G} & 0 \\ 0 & 0\end{array}\right], \widetilde{\mathrm{K}}=\left[\begin{array}{cc}\mathrm{K} & 0 \\ 0 & 0\end{array}\right]$ are effective square matrices of size $(\mathrm{Q}+4) \times(\mathrm{Q}+4)$.

\section{Forces of Bearing}

A floating-ring bearing consists of an annular ring placed between the sleeve and journal and there is a thin oil film in between them. The bearing mid-plane consists of the circumferential feed grooves and the lubricant is fed from the journal position to sleeve through bunch of feed holes located on the ring. The coordinate system considered is shown in Figure1.

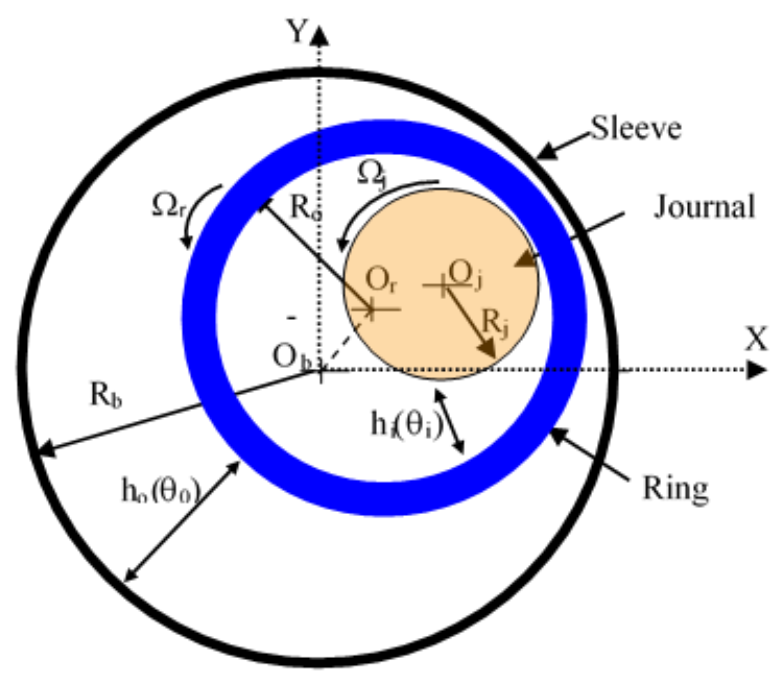

Figure 1. Geometry of the floating-ring bearing.

The hydrodynamic oil film forces can be obtained from the 2-D Reynolds equation with the use of the lubricant pressure distribution. Reynolds equations for both inner and outer lubricant films can be expressed as:

$\frac{1}{\mathrm{R}_{\mathrm{jr}}^{2}} \frac{\partial}{\partial \varphi_{\text {in }}}\left(\frac{\mathrm{h}_{\mathrm{in}}^{3}}{12 \mu_{\mathrm{in}}} \frac{\partial \mathrm{p}_{\mathrm{in}}}{\partial \varphi_{\mathrm{in}}}\right)+\frac{\partial}{\partial \mathrm{z}_{\mathrm{in}}}\left(\frac{\mathrm{h}_{\mathrm{in}}^{3}}{12 \mu_{\mathrm{in}}} \frac{\partial \mathrm{p}_{\mathrm{in}}}{\partial \mathrm{z}_{\mathrm{in}}}\right)=\frac{\Omega_{\mathrm{jr}}+\Omega_{\mathrm{rn}}}{2} \frac{\partial \mathrm{h}_{\text {in }}}{\partial \varphi_{\mathrm{in}}}+\frac{\partial \mathrm{h}_{\text {in }}}{\partial \mathrm{t}}$

$\frac{1}{\mathrm{R}_{\mathrm{ou}}^{2}} \frac{\partial}{\partial \varphi_{\mathrm{ou}}}\left(\frac{\mathrm{h}_{\mathrm{ou}}^{3}}{12 \mu_{\mathrm{ou}}} \frac{\partial \mathrm{p}_{\mathrm{ou}}}{\partial \mathrm{z}_{\mathrm{ou}}}\right)+\frac{\partial}{\partial \mathrm{z}_{\mathrm{ou}}}\left(\frac{\mathrm{h}_{\mathrm{ou}}^{3}}{12 \mu_{\mathrm{ou}}} \frac{\partial \mathrm{p}_{\mathrm{ou}}}{\partial \mathrm{z}_{\mathrm{ou}}}\right)=\frac{\Omega_{\mathrm{rn}}}{2} \frac{\partial \mathrm{h}_{\mathrm{ou}}}{\partial \varphi_{\mathrm{ou}}}+\frac{\partial \mathrm{h}_{\mathrm{ou}}}{\partial \mathrm{t}}$

where $\mathrm{p}$ and $\mu$ represents the lubricant film pressure and viscosity; the subscripts in and ou denote the parameters of inner and outer oil films, respectively. Journal and floating ring bearing parameters are differentiate with the subscripts jr and $\mathrm{rn}$. The journal and floating ring outer radius represented as $\mathrm{R}_{\mathrm{jr}}$ and $\mathrm{R}_{\mathrm{ou}}$. The angular coordinated for inner and outer lubricant film is represented as $\varphi$. The axial coordinates of the inner and outer films are denoted by $z_{\text {in }}$ and $z_{\text {ou }}$ respectively. The oil film thicknesses $h_{i n}, h_{\text {ou }}$ and the 
squeezed terms $\partial \mathrm{h}_{\mathrm{in}} / \partial \mathrm{t}, \partial \mathrm{h}_{\mathrm{ou}} / \partial \mathrm{t}$ can be expressed by considering short length bearing theory as follows:

$$
\begin{aligned}
& \mathrm{h}_{\mathrm{in}}\left(\varphi_{\mathrm{in}}, \mathrm{t}\right)=\mathrm{C}_{\mathrm{in}}-\mathrm{X}_{\mathrm{jr}} \cos \varphi_{\mathrm{in}}-\mathrm{y}_{\mathrm{jr}} \sin \varphi_{\mathrm{in}} \\
& \mathrm{h}_{\mathrm{ou}}\left(\varphi_{\mathrm{ou}}, \mathrm{t}\right)=\mathrm{C}_{\mathrm{ou}}-\mathrm{X}_{\mathrm{rn}} \cos \varphi_{\mathrm{ou}}-\mathrm{Y}_{\mathrm{rn}} \sin \varphi_{\mathrm{oo}} \\
& \frac{\partial \mathrm{h}_{\mathrm{in}}}{\partial \mathrm{t}}=-\left(\dot{\mathrm{x}}_{\mathrm{jr}} \cos \varphi_{\mathrm{in}}-\dot{\mathrm{y}}_{\mathrm{jr}} \sin \varphi_{\mathrm{in}}\right) \\
& \frac{\partial \mathrm{h}_{\mathrm{ou}}}{\partial \mathrm{t}}=-\left(\dot{\mathrm{X}}_{\mathrm{rn}} \cos \varphi_{\mathrm{ou}}-\dot{\mathrm{Y}}_{\mathrm{rn}} \sin \varphi_{\mathrm{o}}\right) \\
& \left\{\begin{array}{l}
\mathrm{x}_{\mathrm{jr}}=\mathrm{X}_{\mathrm{jr}}-\mathrm{X}_{\mathrm{rn}} \\
\mathrm{y}_{\mathrm{jr}}=Y_{\mathrm{jr}}-Y_{\mathrm{rn}}
\end{array}\right. \\
& \left\{\begin{array}{l}
\dot{\mathrm{x}}_{\mathrm{jr}}=\dot{\mathrm{X}}_{\mathrm{jr}}-\dot{X}_{\mathrm{rn}} \\
\dot{\mathrm{y}}_{\mathrm{jr}}=\dot{\mathrm{Y}}_{\mathrm{jr}}-\dot{Y}_{\mathrm{rn}}
\end{array}\right.
\end{aligned}
$$

where $\left(\mathrm{X}_{\mathrm{jr}}, \mathrm{Y}_{\mathrm{jr}}\right)$ are the journal center $\mathrm{O}_{\mathrm{jr}}$ displacement vector in the fixed reference frame. Also, $\mathrm{C}_{\mathrm{in}}$ and $\mathrm{C}_{\mathrm{ou}}$ represent the inner and outer oil film static clearances. The absolute displacement and velocity components of the floating ring center $\mathrm{O}_{\mathrm{rn}}$, are $\left(\mathrm{X}_{\mathrm{rn}}, \mathrm{Y}_{\mathrm{rn}}\right)$ and $\left(\dot{\mathrm{X}}_{\mathrm{rn}}, \dot{\mathrm{Y}}_{\mathrm{rn}}\right)$ while the absolute velocities of centers $\mathrm{O}_{\mathrm{jr}}$ are denoted as $\left(\dot{\mathrm{X}}_{\mathrm{jr}}, \dot{\mathrm{Y}}_{\mathrm{jr}}\right)$. The lower case letters $\left(\mathrm{x}_{\mathrm{jr}} \mathrm{y}_{\mathrm{jr}}\right),\left(\dot{\mathrm{x}}_{\mathrm{jr}}, \dot{\mathrm{y}}_{\mathrm{jr}}\right)$ denote the displacement and velocity components of $\mathrm{O}_{\mathrm{jr}}$ relative to $\mathrm{O}_{\mathrm{rn}}$. The expressions for oil film forces with short bearing approximation can be written as [34]:

$\left\{\begin{array}{l}\mathrm{F}_{\mathrm{ix}} \\ \mathrm{F}_{\mathrm{iy}}\end{array}\right\}=\mu_{\mathrm{in}}\left(\Omega_{\mathrm{jr}}+\Omega_{\mathrm{rn}}\right) \mathrm{R}_{\mathrm{jr}} \mathrm{L}_{\mathrm{in}}\left(\frac{\mathrm{R}_{\mathrm{jr}}}{\mathrm{C}_{\mathrm{in}}}\right)^{2}\left(\frac{\mathrm{L}_{\mathrm{in}}}{2 \mathrm{R}_{\mathrm{jr}}}\right)^{2}\left\{\begin{array}{c}\mathrm{f}_{\mathrm{ix}} \\ \mathrm{f}_{\mathrm{iy}}\end{array}\right\}$

$\left\{\begin{array}{l}F_{\text {ox }} \\ F_{\text {oy }}\end{array}\right\}=\mu_{o u} \Omega_{\text {rn }} R_{\text {ro }} L_{\text {ou }}\left(\frac{R_{\text {oi }}}{C_{\text {ou }}}\right)^{2}\left(\frac{L_{o u}}{2 R_{\text {ro }}}\right)^{2}\left\{\begin{array}{c}f_{\text {ox }} \\ f_{\text {oy }}\end{array}\right\}$

where $f_{i x}, f_{i y}$ and $f_{\text {ox }}, f_{\text {oy }}$ respectively denote the component forces on the journal and bearing. Detailed expressions of these forces are given in the Appendix-A.

\section{Methodology and Optimisation procedure}

The bearing force components are expressed in terms of displacements and velocities in bearing coordinates as:

$\left\{\begin{array}{c}\tilde{\mathrm{F}}_{\mathrm{Bx}} \\ \tilde{\mathrm{F}}_{\mathrm{By}}\end{array}\right\}=\left[\begin{array}{ll}\mathrm{c}_{\mathrm{xx}} & \mathrm{c}_{\mathrm{xy}} \\ \mathrm{c}_{\mathrm{yx}} & \mathrm{c}_{\mathrm{yy}}\end{array}\right]\left\{\begin{array}{l}\dot{\mathrm{x}}_{\mathrm{B}} \\ \dot{\mathrm{y}}_{\mathrm{B}}\end{array}\right\}+\left[\begin{array}{ll}\mathrm{k}_{\mathrm{xx}} & \mathrm{k}_{\mathrm{xy}} \\ \mathrm{k}_{\mathrm{yx}} & \mathrm{k}_{\mathrm{yy}}\end{array}\right]\left\{\begin{array}{l}\mathrm{x}_{\mathrm{B}} \\ \mathrm{y}_{\mathrm{B}}\end{array}\right\}$

where the terms $c$ and $k$ represent the unknown direct and cross-coupled damping and stiffness bearing force coefficients and the suffix $B$ denotes the bearing support location. By substituting these bearing forces in equation (8) and converting into frequency domain, the system of equations can be written as: 


$$
\left\{\begin{array}{l}
F_{x} \\
F_{y}
\end{array}\right\}-\omega^{2} \tilde{M}\left\{\begin{array}{l}
\& X \\
\& Y
\end{array}\right\}=\left[\begin{array}{ll}
H_{x x} & H_{x y} \\
H_{y x} & H_{y y}
\end{array}\right]\left\{\begin{array}{l}
\& X \\
\& Y
\end{array}\right\}
$$

Here, $H_{i j}(\omega)=k_{i j}(\omega)+i \omega c_{i j}(\omega)$ is impedance function, $\left(F_{x}, F_{y}\right)$ and $(X, Y)$ are the discrete Fourier transforms of external forces and displacements respectively. With the knowledge of the component displacements in bending directions at two bearing nodes, it is possible to compute the eight direct coefficients corresponding to each of the two bearings. In order to obtain the correct set of parameters, an error function defined in terms of amplitudes of radial displacements at the bearing nodes is considered at every operating speed. Mathematically, the optimisation problem is defined as:

Minimise $\mathrm{E}=\left(\mathrm{r}_{1(\mathrm{FE})}-\mathrm{r}_{1(\mathrm{~L})}\right)^{2}+\left(\mathrm{r}_{2(\mathrm{FE})}-\mathrm{r}_{2(\mathrm{~L})}\right)^{2}$

where $r_{\mathrm{n}(\mathrm{FE})}=\sqrt{\mathrm{X}_{\mathrm{nFE}}{ }^{2}+\mathrm{Y}_{\mathrm{nFE}}^{2}}$ is the amplitude at bearing-n in radial-direction from actual system, while $r_{n(L)}=\sqrt{X_{n L}^{2}+Y_{n L}^{2}}$ is the radial displacement amplitude at bearing-n from linear bearing force model. This is an implicit function of bearing coefficients, whose upper and lower bounds are considered as: $\mathrm{k}_{\mathrm{i}} \in\left[\mathrm{k}_{\min }, \mathrm{k}_{\max }\right]$ and $\mathrm{c}_{\mathrm{i}} \in\left[\mathrm{c}_{\min }, \mathrm{c}_{\max }\right]$ with $\mathrm{i}=\mathrm{x}, \mathrm{y}$. The minimisation problem is highly nonlinear function of the stiffness and damping parameters and requires a robust optimisation algorithm.

\section{Particle Swarm Optimisation (PSO)}

Particle swarm optimisation scheme is one of the robust metaheuristic optimisation schemes based on the behavior of flocking bird/fish in food search [35]. Initially with the unspecified set of solutions, the system starts and look for optimum solution by updating the generations. Particle is described as each candidate solution and set of particles is known as swarm. In a cooperative manner they move in n-dimensional search space. The variable which performs the Swarm movement is called velocity. This velocity is influenced by social and local factors. $P_{\text {best }}$ is the best position identified so far in the search space and $G_{b e s t}$ is the best position identified by the swarm. In search space $R^{k}$ (with $\mathrm{k}$ initial sets) for each particle, the objective function value is calculated. If $\mathrm{S}(\mathrm{n})$ and $\operatorname{Vel}(\mathrm{n})$ are each particle position and velocity at $\mathrm{n}^{\text {th }}$ iteration, there are three major factors which influence the movements of each particle. Those are (i) own direction search of particle (ii) particle best position itself (iii) whole swarm best position. The position and velocity of every particle after iteration number $n$ is updated using the following equation.

$\operatorname{Vel}(n+1)=u \times \operatorname{Vel}(n)+c_{1} r_{1}\left(P_{\text {best }}-S(n)\right)+c_{2} r_{2}\left(G_{\text {best }}-S(n)\right)$

$\mathrm{S}(\mathrm{n}+1)=\mathrm{S}(\mathrm{n})+\operatorname{Vel}(\mathrm{n}+1)$

where $\mathrm{u}$ is called inertia factor of the particle, which often reduced in every cycle. Acceleration coefficients $c_{1}$ and $c_{2}$ describe the private (cognitive) and global (social) behavior of the system. Also, the random numbers $r_{1}$ and $r_{2}$ are considered in-between 0 and 1. Till the current iteration $P_{\text {best }}$ is the particle best position. while $G_{\text {best }}$ is the best position of the group until current iteration. The algorithm converges to a best swarm by selecting correct values of $\mathrm{u}, \mathrm{c}_{1}$ and $\mathrm{c}_{2}$. Further, the velocity of the particle is bounded 
between minimum and maximum values. In order to improve accurate and faster convergence, a modification is employed.

\section{Modified Particle Swarm Optimisation (MPSO)}

In order to attain faster convergence without loss of accuracy, several modifications were suggested. To improve the population diversity and PSO's performance, mutation is a powerful strategy [36]. Here, a correction to the updated vector $S(n+1)$ in every cycle is introduced. This approach evaluates a mutation vector created from randomly selected three swarms (vectors, $Y_{B 1}, Y_{B 2}$ and $Y_{B 3}$ ) in that generation. Mathematically, mutation vector $\left(Y_{m u t}\right)$ is expressed as [37]:

$\mathrm{Y}_{\mathrm{mut}}=\mathrm{Y}_{\mathrm{B} 1}+\gamma^{*}\left(\mathrm{Y}_{\mathrm{B} 2}-\mathrm{Y}_{\mathrm{B} 3}\right)$

where $\gamma * \in[0.9,1]$.is the mutation constant The resultant population is modified using this mutation vector according to the following rule.

$Y_{\text {new }, i}=\left\{\begin{array}{cl}Y_{\text {mut }, i,} & \text { if }\left(\text { rand }<p_{\text {Cross }}\right) \\ Y_{i}, & \text { otherwise }\end{array}\right.$ for $\mathrm{i}=1,2, \ldots \mathrm{k}$

Here, $k$ is the number of points in the population (swarm size). The $p_{\text {cross }}$ is crossover probability selected in the range of 0.1 to 0.9 .

\section{RESULTS AND DISCUSSION}

The error between the actual response from the system and idealised response from the linear model is minimised by proper adjustment of the stiffness and damping parameters of the linear model. In order to illustrate the approach, three cases are considered. In the first case, the idealised system and actual system are both linear models, while in the second case actual system is nonlinear and in third case an experimental data is used as actual response. In all the simulated cases, the rotor is analysed using finite element model with Timoshenko beam elements as shown in Figure 2. [1] The two disc masses are mounted at nodes 1 and 9, while the nodes 3 and 7 denote the bearings. Dimensional data of the rotor-bearing system is depicted in Table 1.

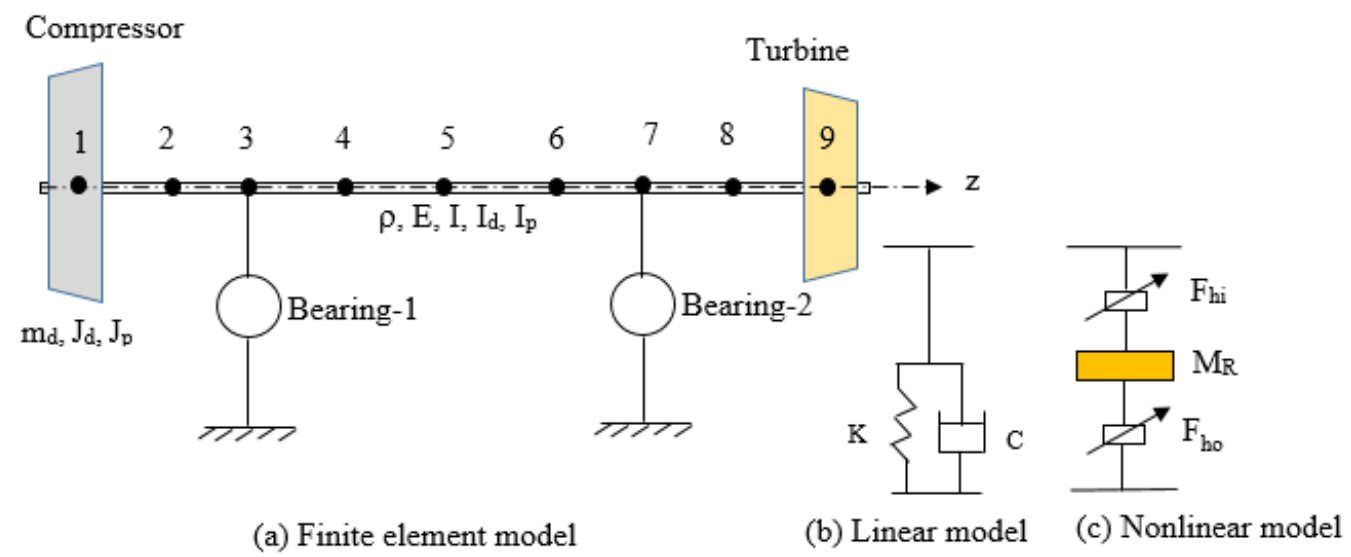

Figure 2. FE model considered for analysis. 
Table 1. Data and material properties of rotor-system [3].

\begin{tabular}{lc}
\hline Properties & Value \\
\hline Shaft material density, $\rho\left(\mathrm{kg} / \mathrm{m}^{3}\right)$ & 7800 \\
Left disk mass, $\mathrm{M}_{\mathrm{DL}}(\mathrm{kg})$ & 1.4 \\
Right disk mass, $\mathrm{M}_{\mathrm{DR}}(\mathrm{kg})$ & 1 \\
Left disk dimeter moment of inertia, $\mathrm{I}_{\mathrm{DL}}\left(\mathrm{kgm}^{2}\right)$ & $6.3 \times 10^{-4}$ \\
Right disk diameter moment of inertia, $\mathrm{I}_{\mathrm{DR}}\left(\mathrm{kgm}^{2}\right)$ & $4.5 \times 10^{-4}$ \\
Left disk polar moment of inertia, $\mathrm{J}_{\mathrm{DL}}\left(\mathrm{kgm}^{2}\right)$ & $1.26 \times 10^{-5}$ \\
Right disk polar moment of inertia, $\mathrm{J}_{\mathrm{DR}}\left(\mathrm{kgm}^{2}\right)$ & $9 \times 10^{-4}$ \\
Rotor diameter, $\mathrm{D}_{\text {rotor }}(\mathrm{m})$ & 0.02 \\
Rotor Length $(\mathrm{m})$ & 0.4 \\
Young's modulus, E $(\mathrm{GPa})$ & 200 \\
Radius of bearing $(\mathrm{m})$ & 0.01 \\
Length of bearing $(\mathrm{m})$ & 0.01 \\
Radial clearance of bearing (microns) & 200 \\
Viscosity of oil film (Pa-s) & $288 \times 10^{-4}$ \\
Eccentricity (m) & $1 \times 10^{-6}$ \\
\hline
\end{tabular}

The resultant equations are solved by fourth-order Runge-Kutta method with all zero initial conditions. All simulations are carried-out on an Intel core-i7 processor with $3.40 \mathrm{GHz}$ speed and 4 GB RAM. All the codes are implemented in MATLAB R2015a. Figure 3 show the time domain response obtained with reference [38] stiffness and damping values.
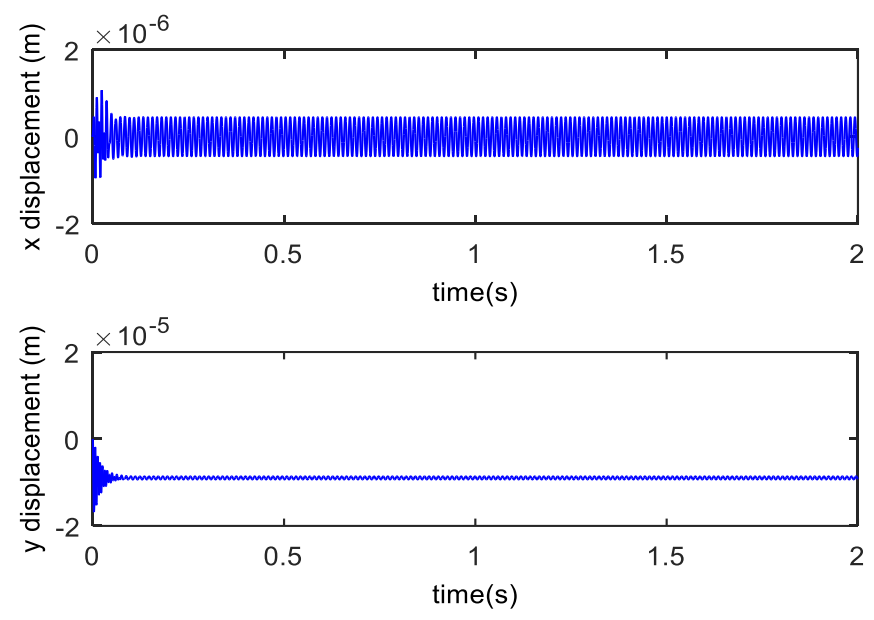

Figure 3. Time domain response at left bearing at rotor speed of $5000 \mathrm{rpm}$

\section{Test Case-1: Actual and Ideal Systems, Both are Linear}

Initially the vibration response of the rotor from known linear bearing parameters is generated. This simulated data is used as a baseline for testing the accuracy of the proposed methodology. The PSO parameters are set as: $\mathrm{c}_{1}=2.1, \mathrm{c}_{2}=2.1$ and $u=u_{\max }-j\left(\frac{u_{\max }-u_{\min }}{j_{\max }}\right)$, where $\mathrm{u}_{\max }$ is maximum weight $\mathrm{u}_{\min }$ is minimum weight, $\mathrm{j}$ is 
iteration number and $j_{\max }$ is maximum iterations. In present work $u_{\max }=0.9$ and $u_{\min }=0.4$ is employed [35]. The variable bounds are taken as: $\mathrm{k}_{\min }=1 \times 10^{5} \mathrm{~N} / \mathrm{m}, \mathrm{k}_{\max }=50 \times 10^{5} \mathrm{~N} / \mathrm{m}$, $\mathrm{c}_{\min }=1 \times 10^{2} \mathrm{~N}-\mathrm{s} / \mathrm{m} \mathrm{c}_{\max }=50 \times 10^{2} \mathrm{~N}-\mathrm{s} / \mathrm{m}$. Figure 4 shows the error as a function of swarm size at $5000 \mathrm{rpm}$. It is seen that the error is minimum at an optimal swarm size of 30 . Table 2 shows the correct and predicted bearing parameters from the linear rotor model at a speed of $5000 \mathrm{rpm}$. The percentage error is found to be less.

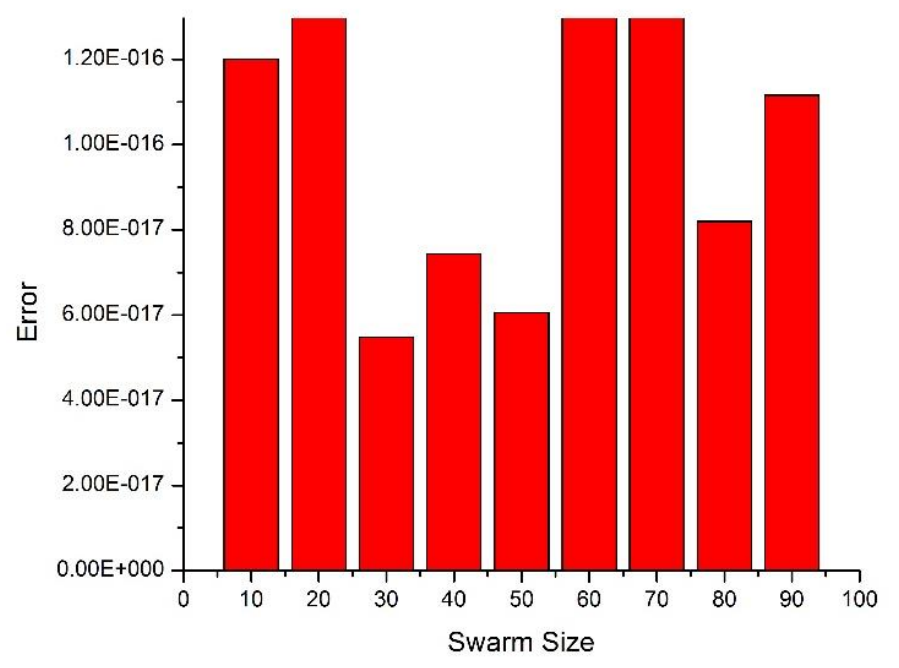

Figure 4. Effect of swarm size in MPSO on final converged error.

Table 2. Assumed and predicted Bearing parameters for linear rotor model at $5000 \mathrm{rpm}$.

\begin{tabular}{lcccc}
\hline Parameter & $\begin{array}{c}\text { Reference } \\
\text { Values [38] }\end{array}$ & $\begin{array}{c}\text { Without } \\
\text { noise }\end{array}$ & $\begin{array}{c}\text { With 5\% } \\
\text { noise }\end{array}$ & $\begin{array}{c}\text { With 10\% } \\
\text { noise }\end{array}$ \\
\hline $\mathrm{k}_{\mathrm{x} 1}(\mathrm{~N} / \mathrm{m})$ & $2.50 \times 10^{5}$ & $2.532 \times 10^{5}$ & $2.554 \times 10^{5}$ & $2.591 \times 10^{5}$ \\
$\mathrm{k}_{\mathrm{y} 1}(\mathrm{~N} / \mathrm{m})$ & $2.75 \times 10^{5}$ & $2.763 \times 10^{5}$ & $2.799 \times 10^{5}$ & $2.825 \times 10^{5}$ \\
$\mathrm{k}_{\mathrm{x} 2}(\mathrm{~N} / \mathrm{m})$ & $2.75 \times 10^{5}$ & $2.778 \times 10^{5}$ & $2.785 \times 10^{5}$ & $2.798 \times 10^{5}$ \\
$\mathrm{k}_{\mathrm{y} 2}(\mathrm{~N} / \mathrm{m})$ & $2.82 \times 10^{5}$ & $2.832 \times 10^{5}$ & $2.892 \times 10^{5}$ & $2.934 \times 10^{5}$ \\
$\mathrm{c}_{\mathrm{x} 1}(\mathrm{Ns} / \mathrm{m})$ & 300 & 303.24 & 303.94 & 304.64 \\
$\mathrm{c}_{\mathrm{y} 1}(\mathrm{Ns} / \mathrm{m})$ & 399 & 400.91 & 401.15 & 402.27 \\
$\mathrm{c}_{\mathrm{x} 2}(\mathrm{Ns} / \mathrm{m})$ & 315 & 316.98 & 317.84 & 319.58 \\
$\mathrm{c}_{\mathrm{y} 2}(\mathrm{Ns} / \mathrm{m})$ & 300 & 302.54 & 302.81 & 303.47 \\
& & & & \\
\hline
\end{tabular}

Figure 5 shows the convergence trend of fitness function using PSO and MPSO approaches. MPSO algorithm converges faster than PSO with same other parameters. In a similar way, the stiffness and damping coefficients are estimated with close accuracy at different rotor speeds. 


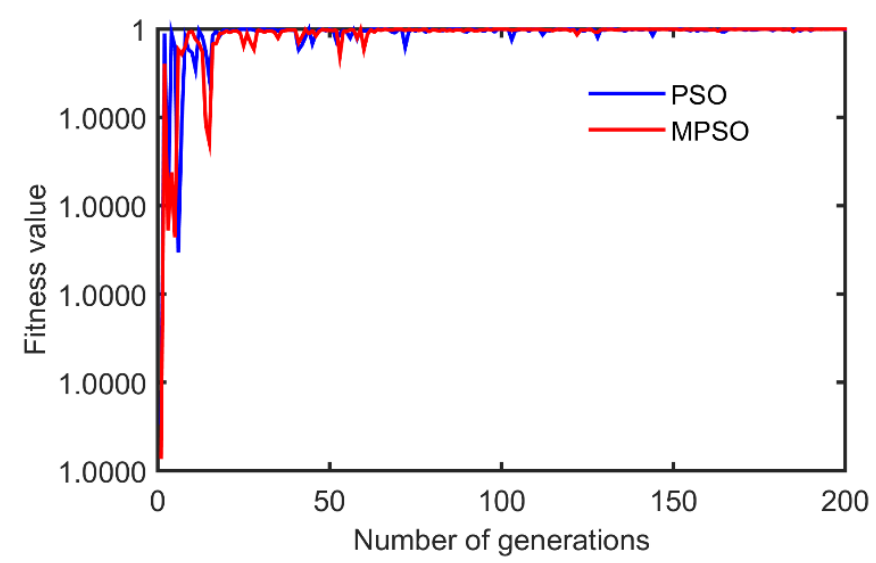

Figure 5. Fitness function convergence in PSO and MPSO.

\section{Test Case-2: System with Nonlinear Bearing Forces}

Here simulated frequency domain data is obtained from FE model of rotor supported over floating-ring bearings. Table 3 shows the parameters of bearing employed in simulation. The time responses and frequency spectra at the bearing nodes in two directions are obtained in different speeds. Figure 6 shows the bearing node frequency spectra at a speed of $5000 \mathrm{rpm}$. There are two critical frequencies $(83.62 \mathrm{~Hz}$ and $160 \mathrm{~Hz})$ as observed from FFT spectra. Furthermore, the subharmonic resonances resulting from hydrodynamic bearing forces are relatively small at this speed of operation [39].

Table 3. Parameters of bearing considered [3].

\begin{tabular}{lc}
\hline Parameter & Value \\
\hline Outer bearing clearance, $\mathrm{C}_{2}(\mathrm{~m})$ & $8 \times 10^{-5}$ \\
Inner bearing clearance, $\mathrm{C}_{1}(\mathrm{~m})$ & $2 \times 10^{-5}$ \\
Floating ring mass, $\mathrm{m}_{\mathrm{r}}(\mathrm{kg})$ & 0.02 \\
Inner oil film viscosity, $\mu_{\mathrm{i}}(\mathrm{Pa}-\mathrm{s})$ & 0.006 \\
Outer oil film viscosity, $\mu_{\mathrm{o}}(\mathrm{Pa}-\mathrm{s})$ & 0.012 \\
\hline
\end{tabular}

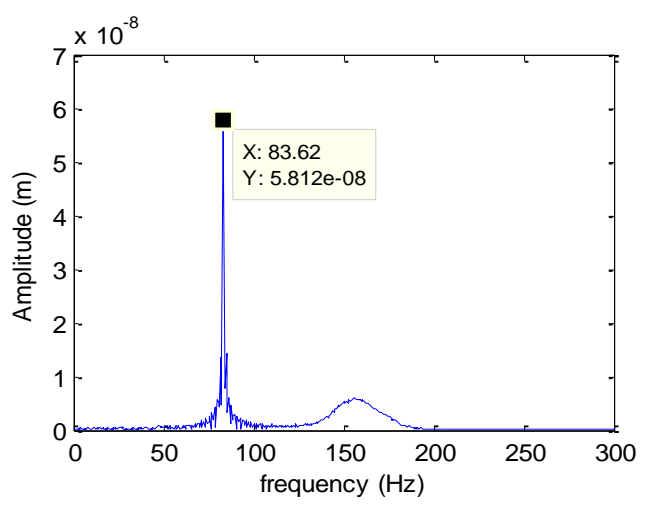

(a)

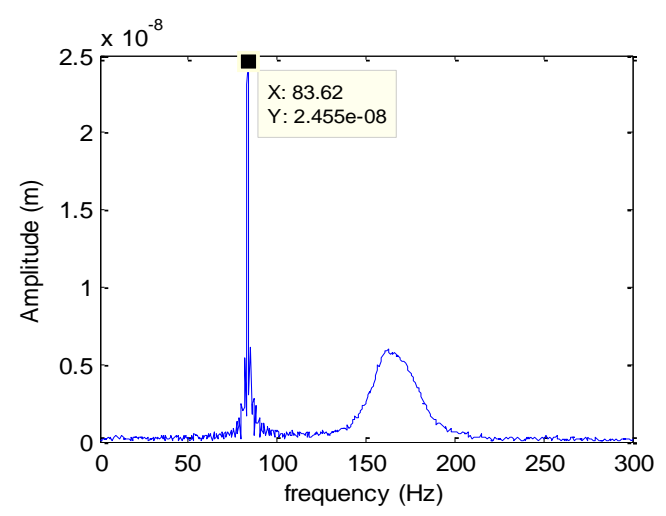

(b)

Figure 6. Frequency spectra at $5000 \mathrm{rpm}$ at (a) left and; (b) right bearing. 
In order to identify the bearing coefficients these response data are given as inputs to the optimisation program at a speed of $5000 \mathrm{rpm}$. The modified particle swarm optimisation scheme is implemented with a swarm size of 30 . In order to test the effectiveness, the minimisation of error function is carried out using two other metaheuristic algorithms namely genetic algorithms (GA) [40] and simulated annealing (SA) [41]. For GA, population sizes of 30 along with mutation and crossover functions respectively as constraint dependent and scattered type were selected. In SA also the function tolerance is considered as $10^{-6}$. The annealing function used is fast annealing type and the reannealing interval is considered to be 100. Figure 7 shows the convergence trends obtained from GA and SA.

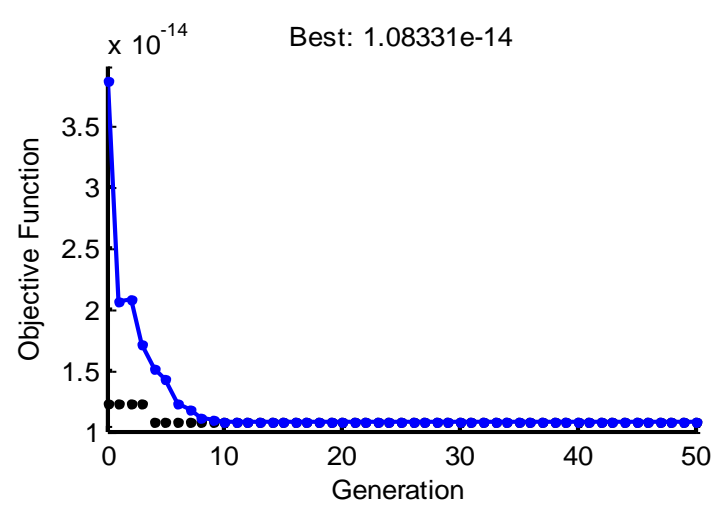

(a)

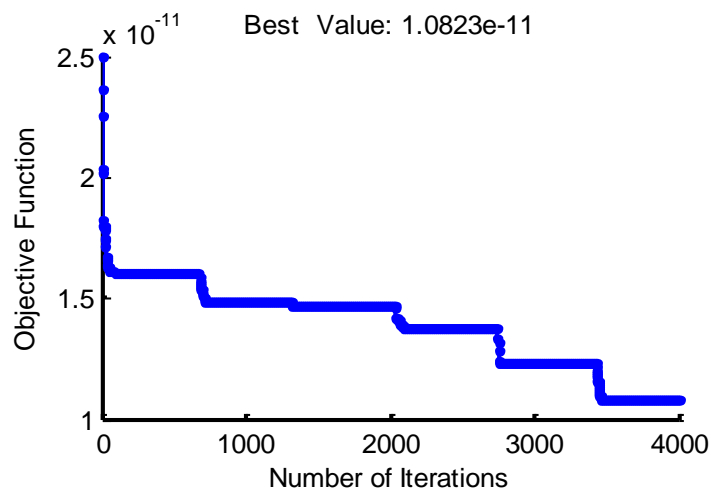

(b)

Figure 7. Convergence trend from (a) GA (b) SA.

The error function value obtained along with the time taken from the two optimisation approaches are depicted in the Table 4 along with MPSO. It is seen that the MPSO achieves relatively a minimum error. The time taken is also small and it also permits minimum number of parameters to alter. The optimum stiffness and damping parameters obtained from the three techniques are found to be close to each other. Table 5 shows the identified stiffness and damping parameters of the bearings at different speeds of the rotor using MPSO. Using these identified linear coefficients, the response amplitudes at left bearing node are plotted as shown in the Figure 8. The amplitudes from input simulated data with nonlinear bearing force model are also depicted for comparison.

Table 4. Error obtained from the three optimisation techniques.

\begin{tabular}{lccc}
\hline Sl.no & \multicolumn{2}{c}{ Error } & Time (s) \\
\hline 1 & MPSO & $5.49 \mathrm{e}-17$ & 140 \\
2 & GA & $1.083 \mathrm{e}-14$ & 155 \\
3 & SA & $1.082 \mathrm{e}-11$ & 185 \\
\hline
\end{tabular}

The amplitudes are matching at lower speeds of operation in both the directions. Due to minimisation of the radial error, the identified amplitudes are close in Y-direction compared to X-direction beyond $5000 \mathrm{rpm}$. This may be due to the amplitudes in the $\mathrm{Y}$ direction are of two orders of more magnitude those in $\mathrm{X}$-direction, resulting in a $\mathrm{Y}$ direction fitting for error function. This is due to nonlinear objective error function of radial amplitudes accounted in this work, instead of errors in individual directions. More unified non-dimensional amplitudes would lead to improved accuracy. 
Table 5. Identified stiffness and damping parameters of the bearings at different speeds.

\begin{tabular}{|c|c|c|c|c|c|c|c|c|c|}
\hline \multirow{2}{*}{$\begin{array}{l}\text { Sl. } \\
\text { no }\end{array}$} & \multirow{2}{*}{$\begin{array}{l}\text { Speed } \\
(\mathrm{rpm})\end{array}$} & \multicolumn{2}{|c|}{ Left Bearing } & \multicolumn{2}{|c|}{ Right Bearing } & \multicolumn{2}{|c|}{ Left Bearing } & \multicolumn{2}{|c|}{ Right Bearing } \\
\hline & & $\begin{array}{c}\mathrm{k}_{\mathrm{x} 1} \\
(\mathrm{MN} / \mathrm{m})\end{array}$ & $\begin{array}{c}\mathrm{k}_{\mathrm{y} 1} \\
(\mathrm{MN} / \mathrm{m})\end{array}$ & $\begin{array}{c}\mathrm{k}_{\mathrm{x} 2} \\
(\mathrm{MN} / \mathrm{m})\end{array}$ & $\begin{array}{c}\mathrm{k}_{\mathrm{y} 2} \\
(\mathrm{MN} / \mathrm{m})\end{array}$ & $\begin{array}{c}\mathrm{c}_{\mathrm{x} 1} \\
(\mathrm{MNs} / \mathrm{m})\end{array}$ & $\begin{array}{c}\mathrm{c}_{\mathrm{y} 1} \\
(\mathrm{MNs} / \mathrm{m})\end{array}$ & $\begin{array}{c}\mathrm{c}_{\mathrm{x} 2} \\
(\mathrm{MNs} / \mathrm{m})\end{array}$ & $\begin{array}{c}c_{\mathrm{y} 2} \\
(\mathrm{MNs} / \mathrm{m})\end{array}$ \\
\hline 1 & 1000 & 3.243912 & 3.297501 & 2.945741 & 1.146827 & 0.004804 & 0.000534 & 0.001923 & 0.00291 \\
\hline 2 & 2000 & 4.457859 & 5.014308 & 4.531343 & 0.069801 & 0.002209 & 0.002238 & 0.002352 & 0.002029 \\
\hline 3 & 3000 & 2.512968 & 4.077986 & 2.921957 & 3.513257 & 0.000595 & 0.003738 & 0.004323 & 0.003139 \\
\hline 4 & 4000 & 7.167609 & 3.371391 & 2.631405 & 1.558222 & 0.000454 & 0.002924 & 0.004957 & 0.000815 \\
\hline 5 & 5000 & 4.274167 & 0.884001 & 3.113408 & 0.637015 & 0.004408 & 0.000748 & 0.005085 & 0.00461 \\
\hline 6 & 6000 & 3.225923 & 2.8166 & 1.386198 & 4.635 & 0.002287 & 75 & 004933 & 0.002182 \\
\hline 7 & 7000 & 1587 & 4.79 & 2.560 & & 118 & & & 314 \\
\hline 8 & 8000 & 5.679481 & 0.366957 & 3.234727 & 1.19 & 0.001133 & 0.000502 & 0.003877 & 0.002208 \\
\hline 9 & 9000 & 2.673076 & 4.25677 & 3.327847 & 1.343291 & 0.001606 & 0.003849 & 0.005516 & 0.002693 \\
\hline 10 & 10000 & 4.303907 & 0.753432 & 4.143091 & 1.760073 & 0.002671 & 0.004216 & 0.003178 & 0.003742 \\
\hline
\end{tabular}

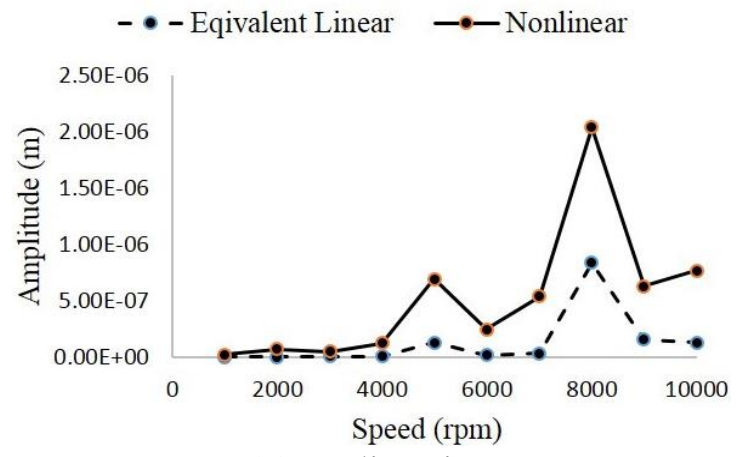

(a) X-direction

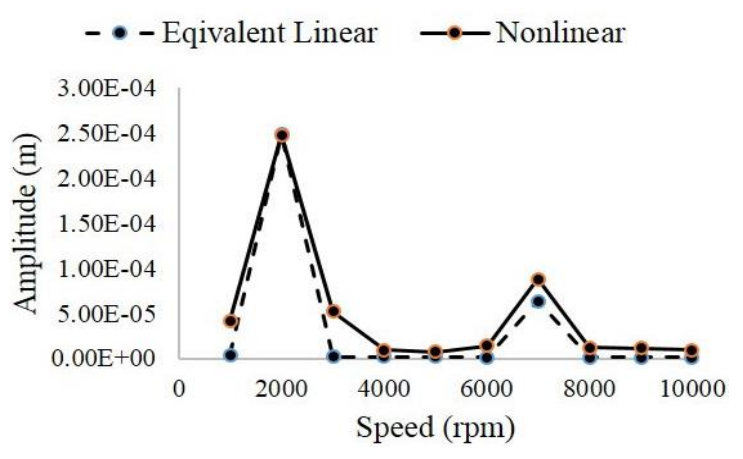

(b) Y-direction

Figure 8. Comparison of vibration amplitudes at left bearing in $\mathrm{X}$ and $\mathrm{Y}$-direction.

\section{Test Case-3: Parameter Identification from Experimental Data}

In order to further test the methodology, an experimental analysis is conducted on a dual disk rotor mounted over two oil-film bearings. Figure 9 shows the schematic of an inhouse fabricated rotor bearing system operated with a single-phase AC motor. Two accelerometers (PG $109 \mathrm{Mo}, 1-10 \mathrm{kHz}$ ) are mounted on each bearing in lateral directions to measure the rotor displacements. Both the input and output signals are recorded with a four-channel digital storage oscilloscope (Tektronix, model- DPO 43034) for recording the signals. A similar set of observations are noted at the other bearing. Table 6 shows the geometric and material parameters of the rotor system. Two similar hydrodynamic journal bearings (SKF UCP 204, $12.8 \mathrm{KN}$ ) are employed for supporting the rotor.

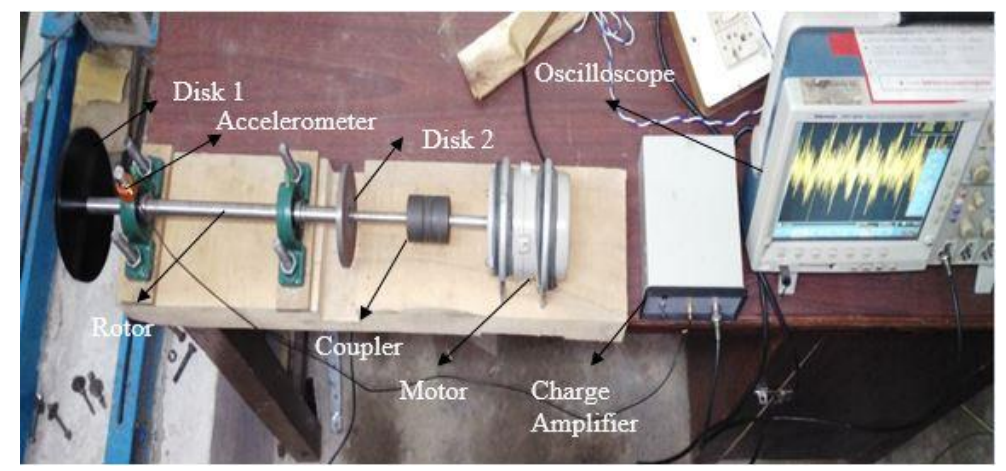

Figure 9. Experimental rotor model employed. 
Table 6. Experimental system data.

\begin{tabular}{lc}
\hline Properties & Value \\
\hline Shaft material density $\left(\mathrm{kg} / \mathrm{m}^{3}\right)$ & 7800 \\
Left disk mass, $M_{\text {DL }}(\mathrm{kg})$ & 1.4 \\
Right disc mass, $M_{\text {DR }}(\mathrm{kg})$ & 1 \\
Rotor diameter, $\mathrm{D}_{\mathrm{sh}}(\mathrm{m})$ & 0.016 \\
Rotor length $(\mathrm{m})$ & 0.48 \\
Young's modulus, E $(\mathrm{GPa})$ & 200 \\
Distance between the bearings $(\mathrm{m})$ & 0.22 \\
Distance from Disc1 to left bearing & 0.09 \\
Distance from Disc2 to right bearing & 0.09 \\
\hline
\end{tabular}

Figure 10 shows the time history and FFT plots obtained from the experimental analysis at the left bearing node in two directions at rotor speed of $900 \mathrm{rpm}$. Likewise, the time history and FFT plots at the right bearing in two directions are also recorded. Unlike in simulation results, the operating speed is limited by the motor employed in the test setup which is up to $900 \mathrm{rpm}$. However, the identification approach can be tested at any speed of rotor operation.

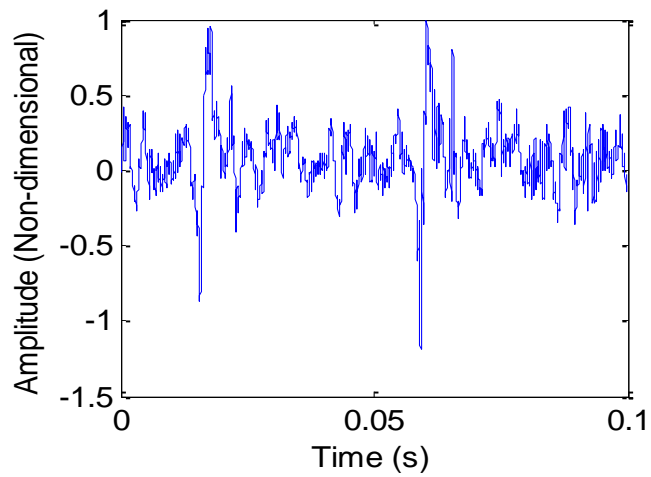

(a) X-direction

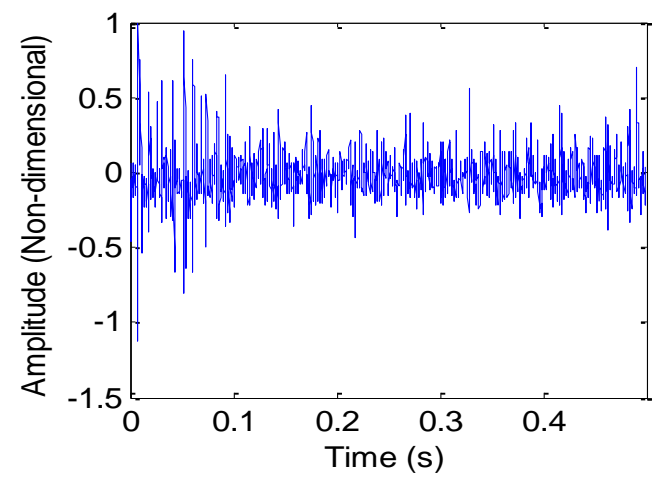

(c) Y-direction

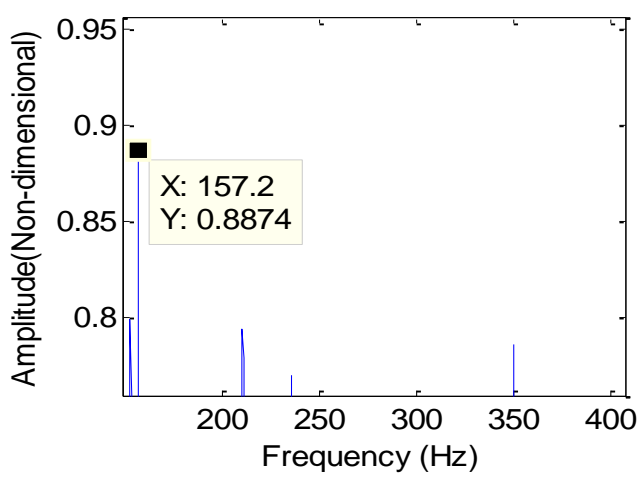

(b) X-direction

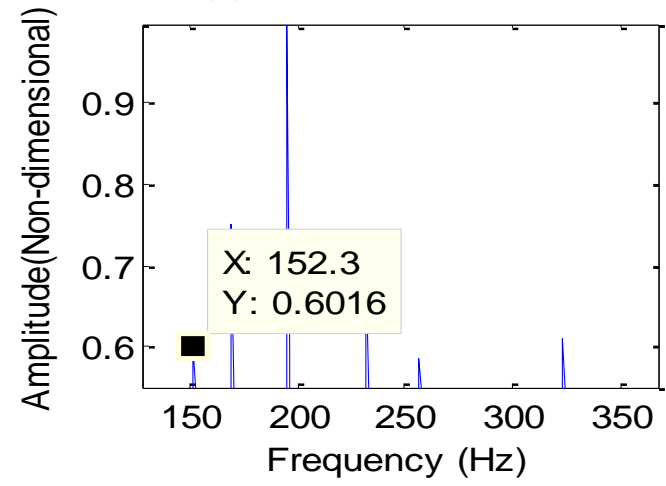

(d) Y-direction

Figure 10. Time history and FFT plots at the left bearing.

Using these frequency spectra, the amplitudes at the two bearings in $\mathrm{X}$ and $\mathrm{Y}$ directions are noted down. With proposed methodology of identification, stiffness and damping parameters are estimated using MPSO algorithm. Figure 11 shows the estimated linear stiffness and damping parameters at the two bearing nodes corresponding to 900 
rpm. Figure 12 shows the frequency responses obtained from the measured coefficients. It is seen that the first resonant peak occurs at $159 \mathrm{~Hz}$ coming close to the experimentally obtained value $(157.2 \mathrm{~Hz})$. However, the other modes are not comparatively dominant.

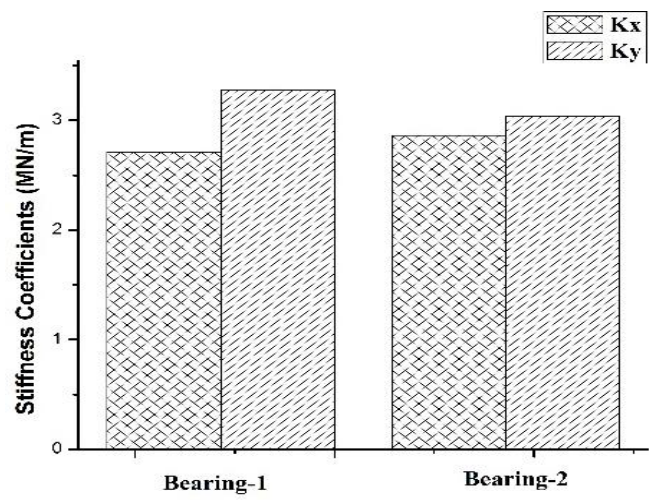

(a) Stiffness coefficients

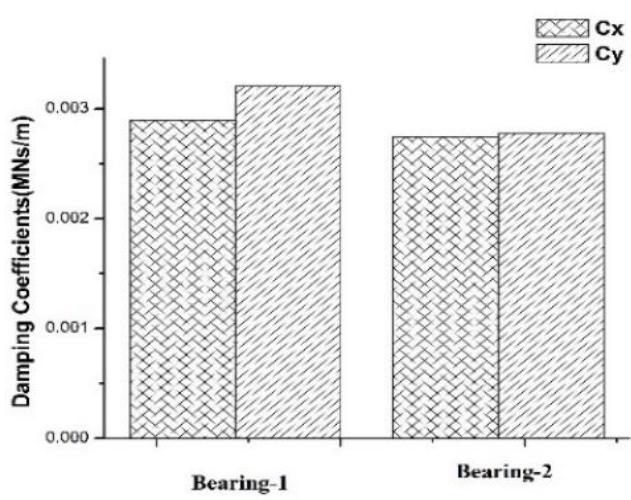

(b) Damping coefficients.

Figure 11. Identified bearing parameters.

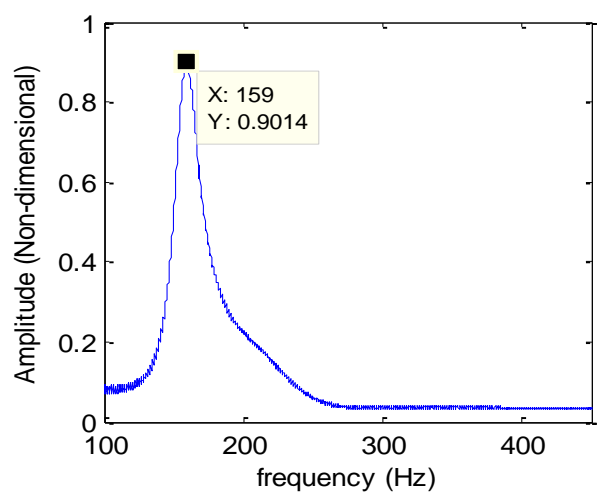

(a) X-direction

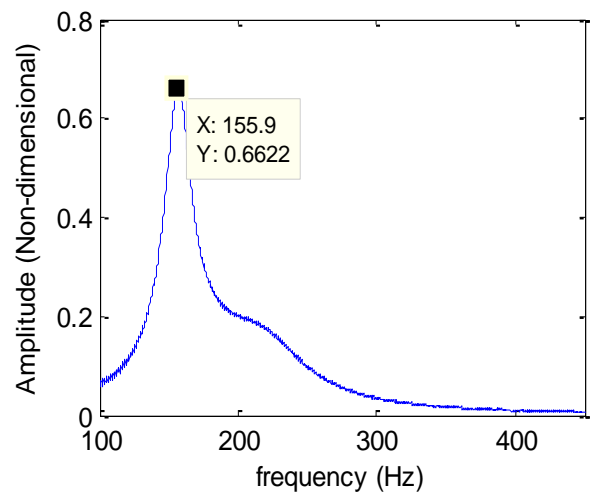

(b) Y-direction.

Figure 12. Frequency spectra at left bearing.

\section{CONCLUSION}

An optimisation-based bearing parameter identification procedure was illustrated from the dynamic response in a dual disk rotor dynamic model. Flexible rotor system was analysed with finite element model and the responses in frequency domain have been obtained at different speeds using nonlinear bearing forces. The error function defined as a difference of actual and ideal response amplitudes was minimised with modified particle swarm optimisation scheme. The approach was further tested with vibration response data obtained from an experimental test rotor supported on hydrodynamic radial bearings. The methodology is reliable and predicts the coefficients with limited computation effort. Unlike existing methods of identification, present approach can estimate the equivalent bearing parameters from nonlinear force models and with experimental data. The average time can be further minimised by using approximate solution technique for nonlinear dynamic equations that predicts the frequency spectra without need of time responses or by using a surrogate model to avoid the time-domain simulations. It is also possible to predict cross coupling stiffness and damping coefficients as well as nonlinear stiffness coefficients at the bearings. 


\section{ACKNOWLEDGEMENT}

The authors are grateful to the National Institute of Technology, Rourkela, Odisha, India for extending their facilities to carry out the research work.

\section{REFERENCES}

[1] Li CH. Dynamics of rotor bearing systems supported by floating ring bearings. Journal of Lubrication Technology. 1982; 104 (4): 469-76.

[2] Zhang H, Shi Z, Zhen D, Gu F, Ball A. Stability Analysis of a Turbocharger Rotor System Supported on Floating Ring Bearings. Journal of Physics: Conference Series: IOP Publishing; 2012. p. 012032.

[3] Zhang H, Shi Z, Zhang S, Gu F. Stability analysis for a turbocharger rotor system under nonlinear hydrodynamic forces. Scientific Research and Essays. 2013; 8 (31): $1495-511$.

[4] Wang L, Bin G, Li X, Zhang X. Effects of floating ring bearing manufacturing tolerance clearances on the dynamic characteristics for turbocharger. Chinese Journal of Mechanical Engineering. 2015; 28(3): 530-40.

[5] Meruane V, Pascual R. Identification of nonlinear dynamic coefficients in plain journal bearings. Tribology International. 2008; 41(8):743-54.

[6] Kozánek J, Šimek J, Steinbauer P, Bílkovský A. Identification of stiffness and damping coefficients of aerostatic journal bearing. Engineering Mechanics. 2009; 16(3): 209-20.

[7] Choy F, Braun M, Hu Y. Nonlinear effects in a plain journal bearing: part 1analytical study. Journal of Tribology. 1991; 113(3): 555-61.

[8] Tieu A, Qiu Z. Identification of sixteen dynamic coefficients of two journal bearings from experimental unbalance responses. Wear. 1994; 177(1): 63-9.

[9] Qiu Z, Tieu A. Identification of sixteen force coefficients of two journal bearings from impulse responses. Wear. 1997; 212(2):206-12.

[10] Jiang K, Zhu C, Chen L, Qiao X. Multi-DOF rotor model based measurement of stiffness and damping for active magnetic bearing using multi-frequency excitation. Mechanical Systems and Signal Processing. 2015; 60: 358-74.

[11] Zhou J, Di L, Cheng C, Xu Y, Lin Z. A rotor unbalance response based approach to the identification of the closed-loop stiffness and damping coefficients of active magnetic bearings. Mechanical Systems and Signal Processing. 2016; 66: 665-78.

[12] Xu Y, Zhou J, Di L, Zhao C. Active magnetic bearings dynamic parameters identification from experimental rotor unbalance response. Mechanical Systems and Signal Processing. 2017; 83: 228-40.

[13] Jin $\mathrm{C}, \mathrm{Xu} \mathrm{Y,} \mathrm{Zhou} \mathrm{J,} \mathrm{Cheng} \mathrm{C.} \mathrm{Active} \mathrm{magnetic} \mathrm{bearings} \mathrm{stiffness} \mathrm{and} \mathrm{damping}$ identification from frequency characteristics of control system. Shock and Vibration. 2016 (3):1-8. http://dx.doi.org/10.1155/2016/1067506

[14] Jacobs W, Boonen R, Sas P, Moens D. The influence of the lubricant film on the stiffness and damping characteristics of a deep groove ball bearing. Mechanical Systems and Signal Processing. 2014; 42(1-2): 335-50.

[15] Peng J-P, Carpino M. Calculation of stiffness and damping coefficients for elastically supported gas foil bearings. Journal of tribology. 1993; 115(1): 20-7.

[16] San Andrés L, Chirathadam TA, Kim T-H. Measurement of structural stiffness and damping coefficients in a metal mesh foil bearing. Journal of engineering for gas turbines and power. 2010; 132(3): 032503. 
[17] Arora V, Van der Hoogt P, Aarts RG, de Boer A. Identification of stiffness and damping characteristics of axial air-foil bearings. International journal of mechanics and materials in design. 2011; 7(3): 231.

[18] Zhang B, Qi S, Feng S, Geng H, Sun Y, Yu L. An experimental investigation of a microturbine simulated rotor supported on multileaf gas foil bearings with backing bump foils. Proceedings of the Institution of Mechanical Engineers, Part J: Journal of Engineering Tribology. 2017; 0(0):1-12. DOI: $10.1177 / 1350650117725463$.

[19] Wilkes JC, Wade J, Rimpel A, Moore J, Swanson E, Grieco J, et al. Impact of bearing clearance on measured stiffness and damping coefficients and thermal performance of a high-stiffness generation 3 foil journal bearing. ASME Turbo Expo 2016: Turbomachinery Technical Conference and Exposition: American Society of Mechanical Engineers; 2016. p. V07BT31A011-V07BT31A.

[20] Czołczyński K. How to obtain stiffness and damping coefficients of gas bearings. Wear. 1996; 201(1-2): 265-75.

[21] Dellacorte C. Stiffness and damping coefficient estimation of compliant surface gas bearings for oil-free turbomachinery. Tribology Transactions. 2011; 54(4): 674-84.

[22] Asgharifard-Sharabiani P, Ahmadian H. Nonlinear model identification of oillubricated tilting pad bearings. Tribology International. 2015; 92: 533-43.

[23] Theisen LR, Niemann HH, Santos IF, Galeazzi R, Blanke M. Modelling and identification for control of gas bearings. Mechanical Systems and Signal Processing. 2016; 70: 1150-70.

[24] Wang W, Liu B, Zhang Y, Shao X, Allaire PE. Theoretical and experimental study on the static and dynamic characteristics of tilting-pad thrust bearing. Tribology International. 2018; 123: 26-36.

[25] Tiwari R, Lees A, Friswell M. Identification of dynamic bearing parameters: a review. Shock and Vibration Digest. 2004; 36(2): 99-124.

[26] Dimond T, Sheth P, Allaire P, He M. Identification methods and test results for tilting pad and fixed geometry journal bearing dynamic coefficients-A review. Shock and vibration. 2009; 16(1): 13-43.

[27] Tawfick SH, El-Shafei A, Mokhtar M. Field Identification of Stiffness and Damping Characteristics of Fluid Film Bearings. ASME Turbo Expo 2008: Power for Land, Sea, and Air: American Society of Mechanical Engineers; 2008. p. 1191-201.

[28] Zhou H, Zhao S, Xu H, Zhu J. An experimental study on oil-film dynamic coefficients. Tribology international. 2004; 37(3): 245-53.

[29] De Santiago OC, San Andrés L. Field Methods for Identification of Bearing Support Parameters: Part I-Identification From Transient Rotor Dynamic Response Due to Impacts. ASME Turbo Expo 2003, collocated with the 2003 International Joint Power Generation Conference: American Society of Mechanical Engineers; 2003. p. 509-17.

[30] Kim YH, Yang BS, Tan AC. Bearing parameter identification of rotor-bearing system using clustering-based hybrid evolutionary algorithm. Structural and Multidisciplinary Optimization. 2007; 33(6): 493-506.

[31] Han F, Guo X, Gao H. Bearing parameter identification of rotor-bearing system based on Kriging surrogate model and evolutionary algorithm. Journal of Sound and Vibration. 2013 ;332(11): 2659-71. 
[32] Han F, Guo X, Mo C, Gao H, Hou P. Parameter identification of nonlinear rotorbearing system based on improved kriging surrogate model. Journal of Vibration and Control. 2017; 23(5): 794-807.

[33] Song Z, Liu Y. Dynamic parameter identification of hydrodynamic bearing-rotor system. Shock and Vibration. 2015 (4):1-7.

[34] Adiletta G, Guido A, Rossi C. Chaotic motions of a rigid rotor in short journal bearings. Nonlinear Dynamics. 1996; 10(3): 251-69.

[35] Eberhart R, Kennedy J. A new optimizer using particle swarm theory. Micro Machine and Human Science, 1995 MHS'95, Proceedings of the Sixth International Symposium on: IEEE; 1995. p. 39-43.

[36] Hu X, Eberhart RC, Shi Y. Swarm intelligence for permutation optimization: a case study of n-queens problem. Swarm intelligence symposium, 2003 SIS'03 Proceedings of the 2003 IEEE: IEEE; 2003. p. 243-6.

[37] Kaboli M, Ghanavati B, Akhlaghi M. A new CMOS pseudo approximation exponential function generator by modified particle swarm optimization algorithm. Integration, the VLSI Journal. 2017; 56: 70-6.

[38] Lal M, Tiwari R. Multi-fault identification in simple rotor-bearing-coupling systems based on forced response measurements. Mechanism and Machine Theory. 2012; 51: 87-109.

[39] Rao J, Rotor dynamics. New Delhi: New Age International New Delhi; 1996

[40] Deb K, Optimization for engineering design: Algorithms and examples. New Delhi: PHI Learning New Delhi; 2012

[41] Kirkpatrick S, Gelatt CD, Vecchi MP. Optimization by simulated annealing. Science. 1983; 220: 671-80.

\section{APPENDIX-A}

The component forces on the journal and bearing are expressed as follows:

$\left\{\begin{array}{l}f_{i x} \\ f_{i y}\end{array}\right\}=-\frac{\sqrt{\left(y_{i}+2 \dot{x}_{i}\right)+\left(x_{i}-2 \dot{y}_{i}\right)}}{\left(1-x_{i} \cos \varphi-y_{i} \sin \varphi\right)}\left\{\begin{array}{l}3 x_{i} V_{i}-\sin \alpha_{i} G_{i}-2 \cos \alpha_{i} F_{i} \\ 3 y_{i} V_{i}-\cos \alpha_{i} G_{i}-2 \sin \alpha_{i} F_{i}\end{array}\right\}$

where $V, G, F, \alpha$ are the lubricant force variants.

$\mathrm{V}_{\mathrm{i}}=\frac{2+\left(\mathrm{y}_{\mathrm{i}} \cos \alpha_{\mathrm{i}}-\mathrm{x}_{\mathrm{i}} \sin \alpha_{\mathrm{i}}\right) \mathrm{G}_{\mathrm{i}}}{\left(1-\mathrm{x}_{\mathrm{i}}^{2}-\mathrm{y}_{\mathrm{i}}^{2}\right)}$

$\mathrm{G}_{\mathrm{i}}=\frac{\pi}{\sqrt{1-\mathrm{x}_{\mathrm{i}}^{2}-\mathrm{y}_{\mathrm{i}}^{2}}}-\frac{2}{\sqrt{1-\mathrm{x}_{\mathrm{i}}^{2}-\mathrm{y}_{\mathrm{i}}^{2}}} \tan ^{-1}\left(\frac{\mathrm{y}_{\mathrm{i}} \cos \alpha_{\mathrm{i}}-\mathrm{x}_{\mathrm{i}} \sin \alpha_{\mathrm{i}}}{\sqrt{1-\mathrm{x}_{\mathrm{i}}^{2}-\mathrm{y}_{\mathrm{i}}^{2}}}\right)$

$\mathrm{F}_{\mathrm{i}}=\frac{\left(\mathrm{x}_{\mathrm{i}} \cos \alpha_{\mathrm{i}}+\mathrm{y}_{\mathrm{i}} \sin \alpha_{\mathrm{i}}\right)}{\left(1-\mathrm{x}_{\mathrm{i}}^{2}-\mathrm{y}_{\mathrm{i}}^{2}\right)}$

$\alpha_{\mathrm{i}}=\tan ^{-1}\left(\frac{\mathrm{y}_{\mathrm{i}}+2 \dot{\mathrm{x}}_{\mathrm{i}}}{\mathrm{x}_{\mathrm{i}}-\dot{\mathrm{y}}_{\mathrm{i}}}\right)-\frac{\pi}{2} \operatorname{sign}\left(\frac{\mathrm{y}_{\mathrm{i}}+2 \dot{\mathrm{x}}_{\mathrm{i}}}{\mathrm{x}_{\mathrm{i}}-\mathrm{y}_{\mathrm{i}}}\right)-\frac{\pi}{2} \operatorname{sign}\left(\mathrm{y}_{\mathrm{i}}+2 \dot{\mathrm{x}}_{\mathrm{i}}\right)$

$\left\{\begin{array}{l}f_{o x} \\ f_{\text {oy }}\end{array}\right\}=-\frac{\sqrt{\left(y_{R}+2 \dot{x}_{R}\right)+\left(x_{R}-2 \dot{y}_{R}\right)}}{\left(1-x_{R} \cos \varphi-y_{R} \sin \varphi\right)}\left\{\begin{array}{l}3 x_{R} V_{0}-\sin \alpha_{0} G_{0}-2 \cos \alpha_{0} F_{0} \\ 3 y_{R} V_{0}-\cos \alpha_{0} G_{0}-2 \sin \alpha_{0} F_{0}\end{array}\right\}$ 
$\mathrm{V}_{\mathrm{o}}=\frac{2+\left(\mathrm{y}_{\mathrm{R}} \cos \alpha_{\mathrm{o}}-\mathrm{x}_{\mathrm{R}} \sin \alpha_{\mathrm{o}}\right) \mathrm{G}_{\mathrm{o}}}{\left(1-\mathrm{x}_{\mathrm{R}}^{2}-\mathrm{y}_{\mathrm{R}}^{2}\right)}$

$\mathrm{G}_{\mathrm{o}}=\frac{\pi}{\sqrt{1-\mathrm{x}_{\mathrm{R}}^{2}-\mathrm{y}_{\mathrm{R}}^{2}}}-\frac{2}{\sqrt{1-\mathrm{x}_{\mathrm{R}}^{2}-\mathrm{y}_{\mathrm{R}}^{2}}} \tan ^{-1}\left(\frac{\mathrm{y}_{\mathrm{R}} \cos \alpha_{\mathrm{o}}-\mathrm{x}_{\mathrm{R}} \sin \alpha_{\mathrm{o}}}{\sqrt{1-\mathrm{x}_{\mathrm{R}}^{2}-\mathrm{y}_{\mathrm{R}}^{2}}}\right)$

$F_{o}=\frac{\left(x_{R} \cos \alpha_{0}+y_{R} \sin \alpha_{o}\right)}{\left(1-x_{R}^{2}-y_{R}^{2}\right)}$

$\alpha_{0}=\tan ^{-1}\left(\frac{y_{R}+2 \dot{x}_{R}}{x_{R}-\dot{y}_{R}}\right)-\frac{\pi}{2} \operatorname{sign}\left(\frac{y_{R}+2 \dot{x}_{R}}{x_{R}-y_{R}}\right)-\frac{\pi}{2} \operatorname{sign}\left(y_{R}+2 \dot{x}_{R}\right)$ 